\title{
Immobilizing Ni (II)-Exchanged Heteropolyacids on Silica as Catalysts for Acid-Catalyzed Esterification Reactions
}

\author{
Qiuyun Zhang ${ }^{1,2 *}$, Dandan Lei', Qianqian Luo', Taoli Deng ${ }^{1}$, Jingsong Cheng ${ }^{1}$, Yutao Zhang², \\ Peihua $\mathrm{Ma}^{3 * *}$ \\ 1 School of Chemistry and Chemical Engineering, Anshun University, Anshun 561000, Guizhou Province, China \\ 2 Engineering Technology Center of Control and Remediation of Soil Contamination of Provincial Science \& Technology Bureau, \\ Anshun University, Anshun 561000, Guizhou Province, China \\ ${ }^{3}$ School of Chemistry and Chemical Engineering, Guizhou University, Guiyang 550025, Guizhou Province, China \\ * First corresponding author, e-mail: qyzhang.asu@gmail.com; ** Second corresponding author, e-mail: phma@gzu.edu.cn
}

Received: 03 August 2019, Accepted: 30 October 2019, Published online: 28 November 2019

\begin{abstract}
Biodiesel was synthesized from oleic acid using $\mathrm{Ni}$ (II)-exchanged heteropolyacids immobilized on silica $\left(\mathrm{Ni}_{0.5} \mathrm{H}_{3} \mathrm{SiW} / \mathrm{SiO}_{2}\right)$ as a solid acid catalyst. Based on detailed analyses of FT-IR, XRD, TG and SEM, the structural, surface and thermal stability of $\mathrm{Ni}_{0.5} \mathrm{H}_{3} \mathrm{SiW} / \mathrm{SiO}{ }_{2}$ were investigated. Obtained results demonstrated that the Keggin structure was well in the immobilization process and possess a high thermal stability. Various esterification reaction conditions and reusability of catalyst were studied. High oleic acid conversion of $81.4 \%$ was observed at a 1:22 mole ratio (oleic acid: methanol), 3 wt. \% catalyst at $70{ }^{\circ} \mathrm{C}$ for $4 \mathrm{~h}$. The $\mathrm{Ni}_{0.5} \mathrm{H}_{3} \mathrm{SiW}_{/} \mathrm{SiO}_{2}$ catalyst was reused for several times and presented relatively stable. More interestingly, the kinetic studies revealed the esterification process was compatible with the first order model, and a lower activation energy was obtained in this catalytic system.
\end{abstract}

Keywords

heteropolyacids, $\mathrm{Ni}$ salts of silicotungstic acid, $\mathrm{SiO}_{2}$, esterification, biodiesel

\section{Introduction}

In recent years, the threats of fossil resource exhaustion and worldwide environmental problems are becoming more serious [1-3]. In this context, the production of biodiesel is considered to have particularly high potential alternative fuel to conventional fossil diesel. Additionally, biodiesel is superior to fossil diesel fuel in terms of good biodegradability, low toxicity, sulfur content, flash point and lubricity characteristics, which prolong engine life [4]. Generally, Biodiesel (fatty acid methyl esters) is produced by esterification or transesterification of free fatty acids (FFAs), vegetable oils and animal fats with low molecular weight alcohols, usually methanol or ethanol, in the presence of an acid/base catalyst $[5,6]$.

In the production process, the expense of the raw materials is the major contributor to the cost of biodiesel production [7]. Thus, the low-cost oils are an economical raw material for the production of biodiesel, such as non-edible vegetable oils and waste oils. However, these oils contain large amounts of free fatty acids, which lead to the deactivation of the alkaline catalysis and even to the formation of soap [8]. To overcome these problems, the esterification for high acid value oils have been performed using acid catalysts. Unfortunately, this homogeneous acid catalysts are corrosive, difficult to recycle, and produce large amounts of waste water $[9,10]$. As solid acid catalysts can be easily removed from the reaction mixture and avoid producing large amount of wastewater contributing to polluting the environment, which is currently an active area of research [11]. A variety of solid acid catalysts are comprehensively reported in literature and applied to produce biodiesel [12, 13].

Amongst several solid acid catalysts developed, the heteropolyacids have been seen as one of the promising option for use in biodiesel production process, owning to its strong Brönsted acidity and high proton mobility [14]. However, high solubility in polar solvents and low specific surface area is two major disadvantages that limit its further application [15]. Because of that, heteropolyacids supported are usually more effective for catalytic reactions [16-18]. Hence, in the present work, the $\mathrm{Ni}$ 
(II)-exchanged heteropolyacids immobilized on silica solid acid catalyst was prepared by a facile synthesis process. The synthesized catalyst was characterized by X-ray diffraction (XRD), scanning electron microscopy (SEM), fourier transform infrared spectroscopy (FT-IR), thermogravimetric analysis (TG), and used as a solid catalyst for the biodiesel of production were investigated via esterification of oleic acid with methanol. Various parameters such as catalyst dosage, molar ratio, temperature, time and reusability of catalyst were examined. Furthermore, the kinetics and activation energy for the as-prepared catalyzed esterification were also assessed.

\section{Materials and methods}

\subsection{Materials}

Silicotungstic acid $\left(\mathrm{H}_{4} \mathrm{SiW}, \mathrm{H}_{4} \mathrm{SiW}_{12} \mathrm{O}_{40} \cdot \mathrm{nH}_{2} \mathrm{O}\right)$, nickel (II) nitrate hexahydrate (AR), silica $\left(\mathrm{SiO}_{2}\right)$, oleic acid (AR), lauric acid (AR, $98 \%$ ), stearic acid (AR, $98 \%$ ), myristic acid (AR, $98 \%$ ), palmitic acid (AR, $98 \%$ ) was purchased from Shanghai Aladdin Industrial Inc. All chemicals were used without further purification, unless otherwise noted.

\subsection{Preparation of the catalysts}

The $\mathrm{SiO}_{2}$ was used as a support for the preparation of $\mathrm{Ni}_{0.5} \mathrm{H}_{3} \mathrm{SiW} / \mathrm{SiO}_{2}$ catalyst. In the typical synthesis, the required quantity of $\mathrm{H}_{4} \mathrm{SiW}(1440 \mathrm{mg})$ as dissolved in $5 \mathrm{ml}$ of deionized water, nickel (II) nitrate $(70 \mathrm{mg}$ ) aqueous solution was added dropwise into the $\mathrm{H}_{4} \mathrm{SiW}$ aqueous solution, and kept stirring for over $3 \mathrm{~h}$ in oil bath with $70-80^{\circ} \mathrm{C}$. Subsequently, the desired amount of $\mathrm{SiO}_{2}(2420 \mathrm{mg})$ was used in the above solution and continue stirred for $1 \mathrm{~h}$, and the obtained solid products were then filtered, washed and dried in an oven at $120^{\circ} \mathrm{C}$ for $12 \mathrm{~h}$. These as-prepared catalyst is denoted as $\mathrm{Ni}_{0.5} \mathrm{H}_{3} \mathrm{SiW} / \mathrm{SiO}_{2}$. For the comparison, using the above procedure, the $\mathrm{Ni}_{0.5} \mathrm{H}_{3} \mathrm{SiW}$ sample was also synthetized. Prior to use, the obtained $\mathrm{Ni}_{0.5} \mathrm{H}_{3} \mathrm{SiW} / \mathrm{SiO}_{2}$ catalyst was dried at $120^{\circ} \mathrm{C}$.

\subsection{Characterization}

XRD spectra were obtained using a D8 Advance equipment using graphite monochromator and monochromatic $\mathrm{CuK} \alpha$ radiation (1.5406 $\AA$ ). FT-IR analyses were obtained using a PerkinElmer spectrum 100 using the $\mathrm{KBr}$ disc technique (4000-400 $\left.\mathrm{cm}^{-1}\right)$. TG has performed on a NETZSCH/STA 409 PC Luxx simultaneous thermal analyzer with a heating rate of $5{ }^{\circ} \mathrm{C} / \mathrm{min}$ under an air flow rate of $20 \mathrm{~mL} / \mathrm{min}$. SEM images were conducted using a Hitachi S4800 scanning electron microscope.

\subsection{Catalytic reaction procedure}

The esterification process was conducted in a threeneck round bottom flask equipped with mechanical stirrer, condenser and thermometer in oil bath to maintain the reaction temperature. In a typical experimental run, the desired amount of oleic acid (lauric, myristic, palmitic or stearic acid) was mixed with the desired amount of catalyst. Then, the required amount of methanol at an appropriate ratio was added, and the reaction mixture was heated at different temperature $\left(20-70{ }^{\circ} \mathrm{C}\right)$ for a desired period of time. After the reaction, the catalysts were separated from the solution by filtration, and water and methanol were removed with a rotary evaporator. The conversion of oleic acid (lauric, myristic, palmitic or stearic acid) could be derived from Eq. (1) [19]:

Conversion $(\%)=\left(1-\alpha_{1} / \alpha_{2}\right) \times 100 \%$,

where $\alpha_{1}$ represents the acid value of raw materials, $\alpha_{2}$ represents the acid value of esterification product. The acid value was determined by ISO 660-2009 standard [20].

\section{Results and discussion}

\subsection{Catalyst characterization}

The FT-IR spectrum of $\mathrm{H}_{4} \mathrm{SiW}, \mathrm{Ni}_{0.5} \mathrm{H}_{3} \mathrm{SiW}, \mathrm{SiO}_{2}$ and $\mathrm{Ni}_{0.5} \mathrm{H}_{3} \mathrm{SiW} / \mathrm{SiO}_{2}$ was given in Fig. 1 (a). As can be seen Fig. 1 (a), the FT-IR curve of $\mathrm{H}_{4} \mathrm{SiW}, \mathrm{Ni}_{0.5} \mathrm{H}_{3} \mathrm{SiW}$ and $\mathrm{Ni}_{0.5} \mathrm{H}_{3} \mathrm{SiW} / \mathrm{SiO}_{2}$ exhibit four strong peaks at 980,927 , 884 and $804 \mathrm{~cm}^{-1}$, which represent the stretching vibrations of $\mathrm{W}=\mathrm{O}, \mathrm{Si}-\mathrm{O}, \mathrm{W}-\mathrm{Oc}-\mathrm{W}$, and $\mathrm{W}-\mathrm{Oe}-\mathrm{W}$, respectively [21], and show the existence of the Keggin structures. This indicated that the Keggin structure of $\mathrm{H}_{4} \mathrm{SiW}$ was still good in the immobilization process. In addition, compared with pure $\mathrm{SiO}_{2}, \mathrm{Ni}_{0.5} \mathrm{H}_{3} \mathrm{SiW} / \mathrm{SiO}_{2}$ exhibits the similar diffraction peaks. The FT-IR spectral results suggested that the $\mathrm{Ni}_{0.5} \mathrm{H}_{3} \mathrm{SiW}$ has been successfully immobilized on the surface of $\mathrm{SiO}_{2}$. The XRD pattern was used to confirm the structure of $\mathrm{Ni}_{0.5} \mathrm{H}_{3} \mathrm{SiW} / \mathrm{SiO}_{2}$ (Fig. 1 (b)). Compared with $\mathrm{H}_{4} \mathrm{SiW}$ and $\mathrm{Ni}_{0.5} \mathrm{H}_{3} \mathrm{SiW}, \mathrm{Ni}_{0.5} \mathrm{H}_{3} \mathrm{SiW} / \mathrm{SiO}_{2}$ also shows the similar diffraction peaks at $8.0^{\circ}, 20.9^{\circ}$, $36.6^{\circ}, 45.9^{\circ}$ and $60.1^{\circ}$ with some deviation. This may be due to the $\mathrm{Ni}_{0.5} \mathrm{H}_{3} \mathrm{SiW} / \mathrm{SiO}_{2}$ composite has an interaction between $\mathrm{Ni}_{0.5} \mathrm{H}_{3} \mathrm{SiW}$ and $\mathrm{SiO}_{2}$. Based on these results, this assures that $\mathrm{Ni}_{0.5} \mathrm{H}_{3} \mathrm{SiW}$ are immobilized on the supported surface successfully. Fig. 1 (c) shows the TG result of $\mathrm{Ni}_{0.5} \mathrm{H}_{3} \mathrm{SiW} / \mathrm{SiO}_{2}$. The slight weight loss before $200^{\circ} \mathrm{C}$ is assignable to the loss of residual solvent or water. No major weight loss occurred above $200{ }^{\circ} \mathrm{C}$ for the composite materials, suggesting a considerably high thermal stability. 

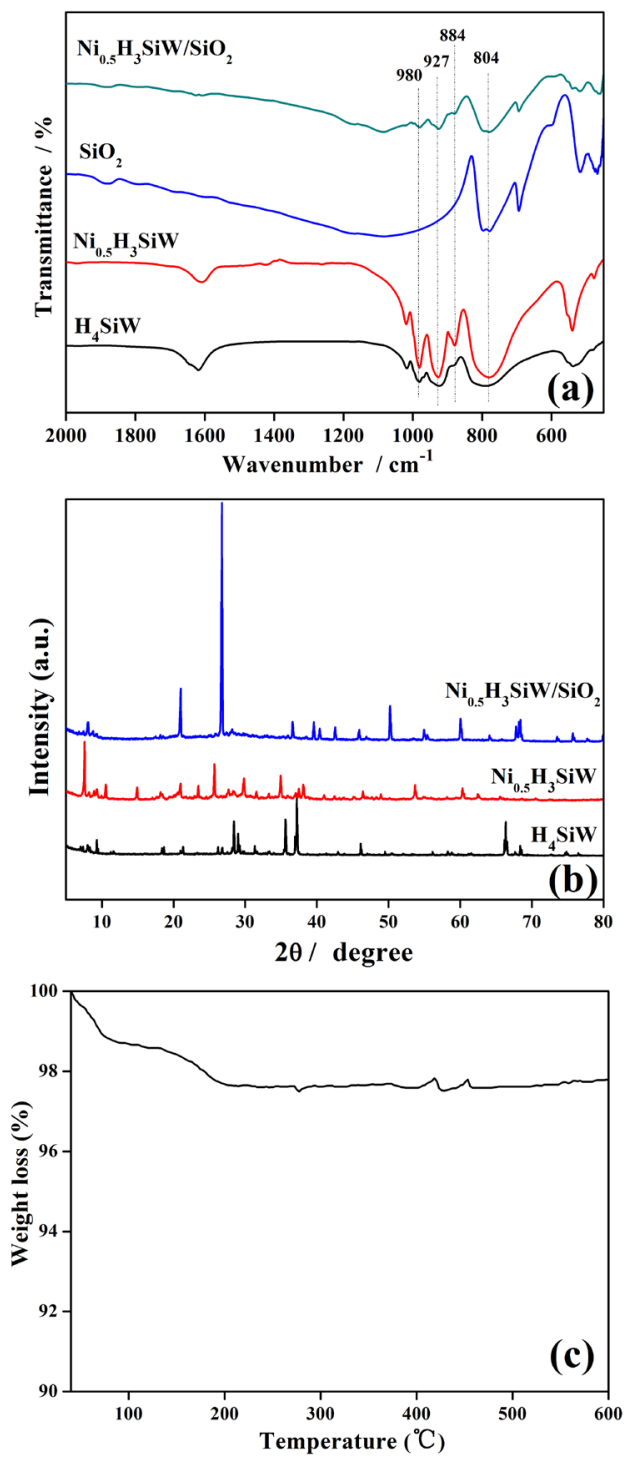

Fig. 1 (a) FT-IR spectra of $\mathrm{H}_{4} \mathrm{SiW}, \mathrm{Ni}_{0.5} \mathrm{H}_{3} \mathrm{SiW}, \mathrm{SiO}_{2}$ and $\mathrm{Ni}_{0.5} \mathrm{H}_{3} \mathrm{SiW} / \mathrm{SiO}_{2}$ (b) XRD patterns of $\mathrm{H}_{4} \mathrm{SiW}, \mathrm{Ni}_{0.5} \mathrm{H}_{3} \mathrm{SiW}$ and

$\mathrm{Ni}_{0.5} \mathrm{H}_{3} \mathrm{SiW} / \mathrm{SiO}_{2}$; (c) TG curve of $\mathrm{Ni}_{0.5} \mathrm{H}_{3} \mathrm{SiW} / \mathrm{SiO}_{2}$.

SEM images of the $\mathrm{H}_{4} \mathrm{SiW}, \quad \mathrm{Ni}_{0.5} \mathrm{H}_{3} \mathrm{SiW}$ and $\mathrm{Ni}_{0.5} \mathrm{H}_{3} \mathrm{SiW} / \mathrm{SiO}_{2}$ samples are shown in Fig. 2 (a)-(c). The images exhibited that the $\mathrm{H}_{4} \mathrm{SiW}$ has a near-cubic blocky structure. After the nickel ion substituted $\mathrm{H}_{4} \mathrm{SiW}$, the $\mathrm{Ni}_{0.5} \mathrm{H}_{3} \mathrm{SiW}$ sample exhibits irregular nano-blocky with the size of around $500 \mathrm{~nm}$. Compared to $\mathrm{H}_{4} \mathrm{SiW}$ and $\mathrm{Ni}_{0.5} \mathrm{H}_{3} \mathrm{SiW}$, as-obtained $\mathrm{Ni}_{0.5} \mathrm{H}_{3} \mathrm{SiW} / \mathrm{SiO}_{2}$ sample exhibits agglomeration of blocky leading to formation of larger blocky, and the irregular nano-blocky of $\mathrm{Ni}_{0.5} \mathrm{H}_{3} \mathrm{SiW}$ were also observed on the surface. Further confirming the $\mathrm{Ni}_{0.5} \mathrm{H}_{3} \mathrm{SiW}$ sample are immobilized on the supported surface, which is in the agreement with the FT-IR and XRD result.

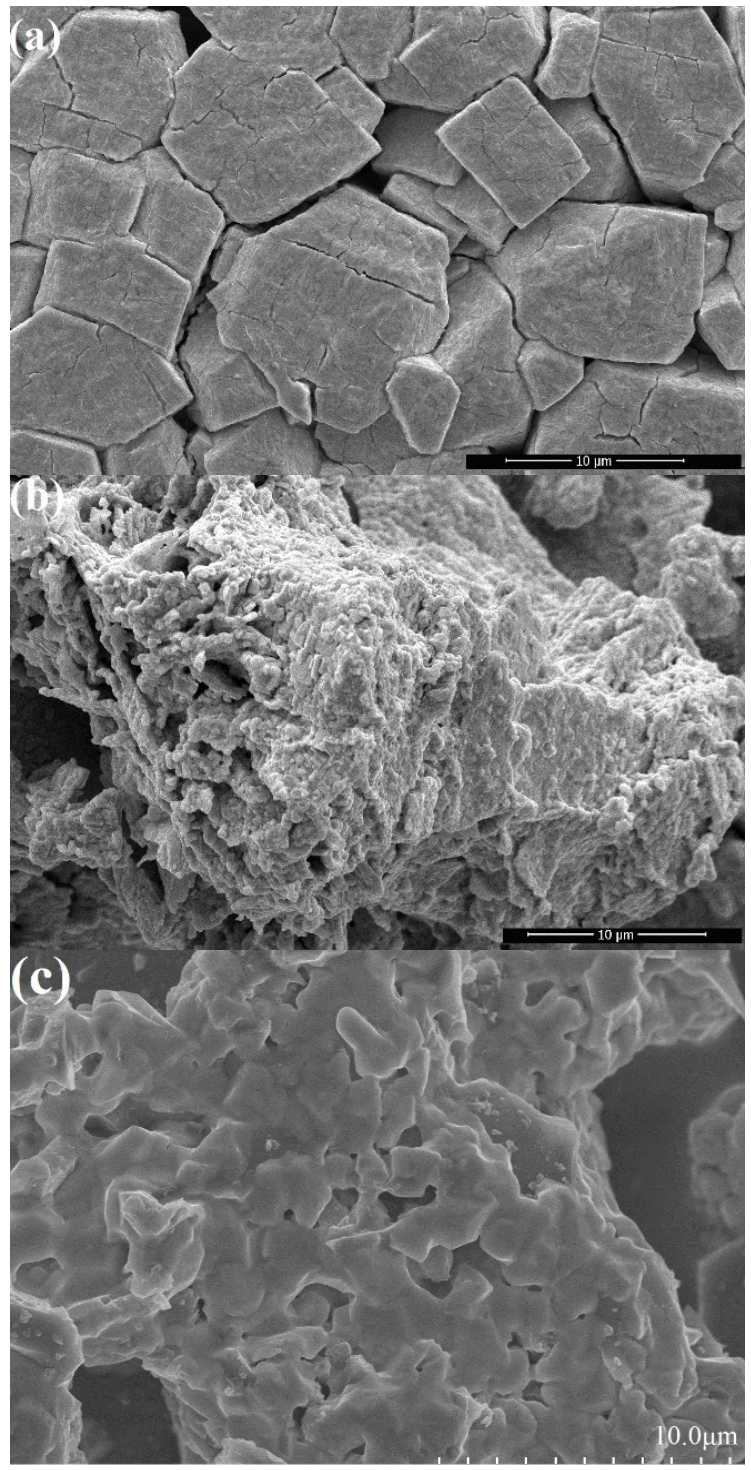

Fig. 2 The SEM image of (a) $\mathrm{H}_{4} \mathrm{SiW}$, (b) $\mathrm{Ni}_{0.5} \mathrm{H}_{3} \mathrm{SiW}$, and (c) $\mathrm{Ni}_{0.5} \mathrm{H}_{3} \mathrm{SiW} / \mathrm{SiO}_{2}$.

\subsection{The catalytic activity of $\mathrm{Ni}_{0.5} \mathrm{H}_{3} \mathrm{SiW} / \mathrm{SiO}{ }_{2}$}

\subsubsection{Effect of reaction time and catalyst dosage}

The reaction time for esterification of oleic acid with methanol catalyzed by 3 wt. $\% \mathrm{Ni}_{0.5} \mathrm{H}_{3} \mathrm{SiW} / \mathrm{SiO}_{2}$ was varied and the results are shown in Fig. 3 (a). The increase in the reaction time enhanced the oleic acid conversion. The conversion obtained improved significantly with increasing reaction time, which can be assigned to slow mass transfer during heterogeneous reaction. $81.4 \%$ oleic acid conversion was found at $4 \mathrm{~h}$ reaction time. Further prolong reaction time, the oleic acid conversion kept rising slowly. Therefore, the suitable reaction time for the esterification 

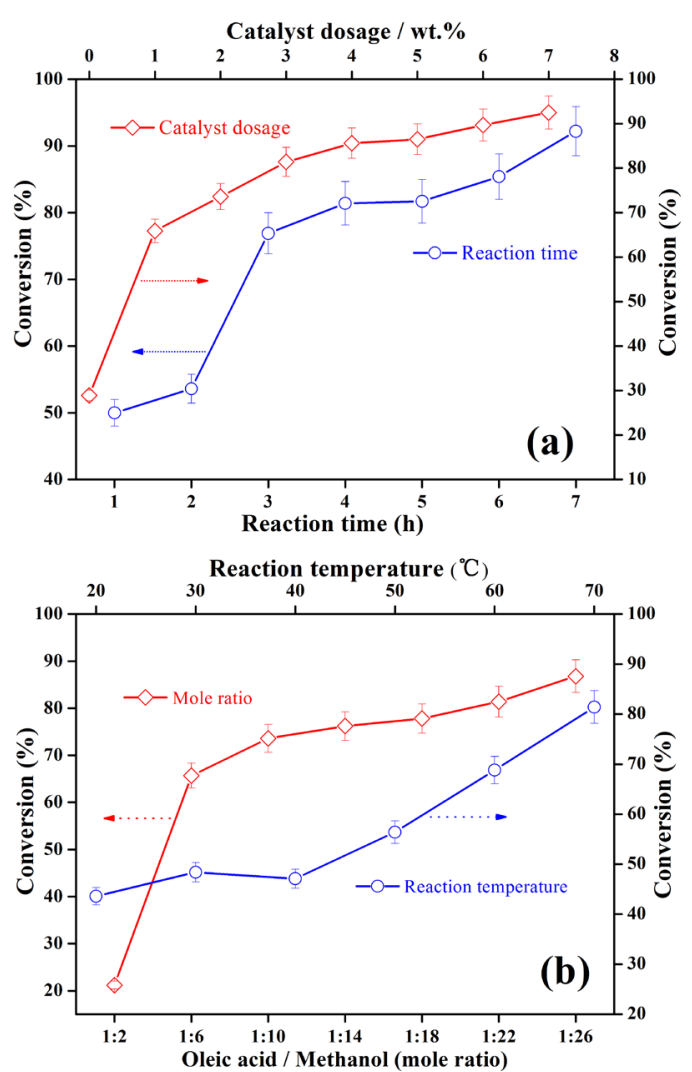

Fig. 3 Influence of esterification process parameters: (a) (a-red: Effect of catalyst dosage; a-blue: Effect of reaction time; b-red: Effect of molar ratio; b-blue: Effect of reaction temperature) on conversion. Reaction conditions: (a-red) oleic acid to methanol molar ratio $1: 22$, reaction temperature $70{ }^{\circ} \mathrm{C}$, reaction time $4 \mathrm{~h}$; (b) (a-blue) oleic acid to methanol molar ratio 1:22, catalyst dosage 3 wt. \%, reaction time $4 \mathrm{~h}$; (b-red) reaction temperature $70{ }^{\circ} \mathrm{C}$, catalyst dosage 3 wt. $\%$, reaction time $4 \mathrm{~h}$; (d-blue) oleic acid to methanol molar ratio $1: 22$, catalyst dosage 3 wt. \%, reaction temperature $70^{\circ} \mathrm{C}$.

reaction is $4 \mathrm{~h}$. Additionally, in the esterification process, the catalyst dosage played an important role on the conversion. The effect of the amount of catalyst on the oleic acid conversion was studied and as shown in Fig. 3 (a). The catalytic activity increased as the dosage of catalyst increased from 0 to $3 \mathrm{wt}$. \%. Interestingly, when the dosage was further increased to $7 \mathrm{wt}$. \%, the conversion had only slight increase. Considering economical efficiency, 3 wt. $\%$ of $\mathrm{Ni}_{0.5} \mathrm{H}_{3} \mathrm{SiW} / \mathrm{SiO}_{2}$ catalyst was selected for subsequent investigations.

\subsubsection{Effect of reaction temperature and molar ratio of oleic acid to methanol}

In order to determine the effect of temperature on the oleic acid esterification, the reaction was conducted at temperatures from 20 to $70{ }^{\circ} \mathrm{C}$. As Fig. 3 (b) shows, it was observed that the conversion increased from 43.6 to $81.4 \%$ when reaction temperature increased from 20 to $70{ }^{\circ} \mathrm{C}$. Further increase of temperature from $70{ }^{\circ} \mathrm{C}$ may lead to lower conversions, it may be due to more evaporation of methanol and enhance the reverse hydrolysis reactions $[22,23]$. Therefore, $70{ }^{\circ} \mathrm{C}$ was suggested to be used for this system. The molar ratio of oleic acid to methanol also has significant impact on esterification. Because of esterification is a reversible reaction, the excessive amount of methanol can increase the oleic acid conversion. Fig. 3 (b) shows the effect of oleic acid to methanol molar ratio on the conversion. The oleic acid conversion gradually increased, when the oleic acid to methanol molar ratio increased from 1:2 to 1:22. However, further increasing of the molar ratio had little effect, and a significant amount of energy is needed to recover a huge amount of unreacted methanol. From the results, the optimum molar ratio of oleic acid to methanol for the oleic acid esterification reaction is approximately 1:22.

In conclusion, the optimum experimental conditions of esterification were 3 wt. $\%$ of $\mathrm{Ni}_{0.5} \mathrm{H}_{3} \mathrm{SiW} / \mathrm{SiO}_{2}$ catalyst amount, 1:22 of oleic acid to methanol molar ratio, $70{ }^{\circ} \mathrm{C}$ of temperature and $4 \mathrm{~h}$ of reaction time. Under the above conditions, the oleic acid conversion could achieve $81.4 \%$.

\subsection{Kinetics of biodiesel production from oleic acid using $\mathrm{Ni}_{0.5} \mathrm{H}_{3} \mathrm{SiW} / \mathrm{SiO}_{2}$ catalyst}

The relationship between time and temperature describes the kinetics of various orders of the esterification reaction and its dependency on reaction rate. Experiments for oleic acid esterification were carried out with the increasing of reaction time at different reaction temperatures $\left(50^{\circ} \mathrm{C}\right.$, $60^{\circ} \mathrm{C}$ and $70{ }^{\circ} \mathrm{C}$ ) as shown in Fig. 4 .

During esterification study, the methanol was used in excess with respect to oleic acid in order to shift

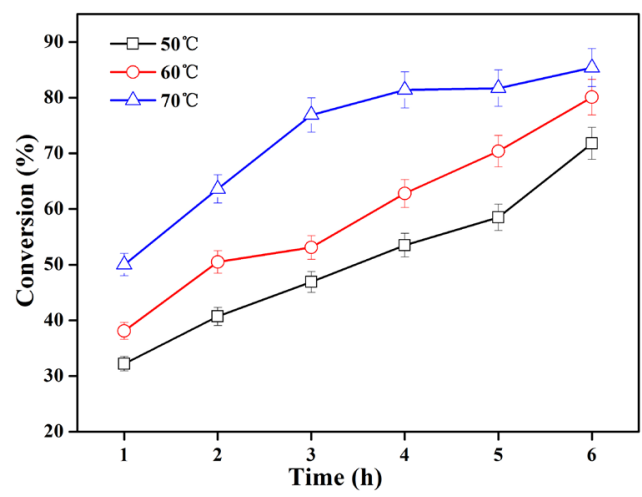

Fig. 4 Effect of time at different temperatures for the oleic acid esterification 
the reaction equilibrium towards the formation of biodiesel. Thus, the esterification reaction kinetics could be treated as a pseudo-first-order. According to previous investigations, Eq. (2) can be reduced to

$-\operatorname{In}(1-X)=k t$,

where $X$ refer to the conversion at the time $t, X$ is the conversion of used oleic acid. The relationship between -In (1-X) and the reaction time $\mathrm{t}$ at different reaction temperatures is shown in Fig. 5 (a). The linear fit of the data supported that the $\mathrm{Ni}_{0.5} \mathrm{H}_{3} \mathrm{SiW} / \mathrm{SiO}_{2}$ catalyzed oleic acid esterification reaction has followed the pseudo first order kinetics.

In addition, in order to calculate the activation energy $\left(E_{a}\right)$, the Arrhenius equation (Eq. (3)) was used:

$\operatorname{In} k=E_{a} / R T+\operatorname{In} A$,

where $A$ is the pre-exponential factor and $R$ is the ideal gas constant. The linear plot of $\operatorname{In} k$ versus $1 / T$ which gives the activation energy is given in Fig. 5 (b). It was found that the activation energy for esterification of oleic acid with methanol using $\mathrm{Ni}_{0.5} \mathrm{H}_{3} \mathrm{SiW} / \mathrm{SiO}_{2}$ as a catalyst is $19.2 \mathrm{~kJ} / \mathrm{mol}$, the $E_{a}$ obtained was lower than that of other research [24, 25]. Very importantly, as previously reported, the reaction is in the kinetic regime when the activation energy exceeds $15 \mathrm{~kJ} / \mathrm{mol}[26,27]$. Therefore, in this study, the kinetic regime is confirmed for the esterification reaction.
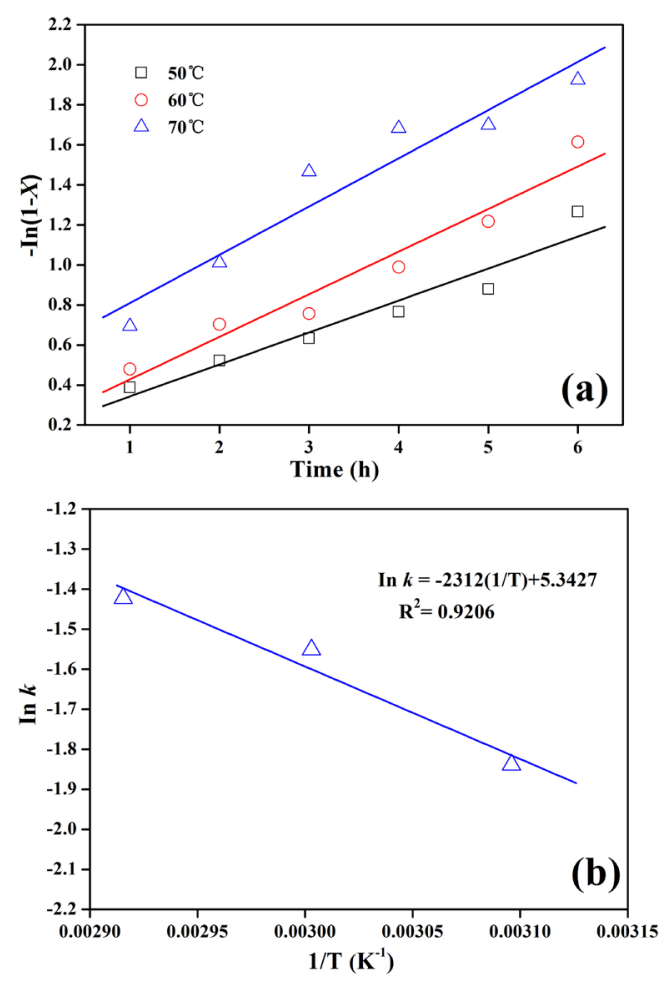

Fig. 5 (a) $-\operatorname{In}(1-X)$ versus time plot at different temperatures, and (b) the plot of In $k$ as a function of $1 / T$ for the esterification reaction.

\subsection{The recycled activity of the catalyst}

Reusability of solid acid catalyst is very important in view-point of practical application. The reusability of the $\mathrm{Ni}_{0.5} \mathrm{H}_{3} \mathrm{SiW} / \mathrm{SiO}_{2}$ catalyst was assessed by the tests performed on oleic acid with methanol. After the reaction course, the $\mathrm{Ni}_{0.5} \mathrm{H}_{3} \mathrm{SiW} / \mathrm{SiO}_{2}$ catalyst was separated by simple filtration from the reaction mixture and then used without any post-treatment before being applied to the next run. The catalytic performance of $\mathrm{Ni}_{0.5} \mathrm{H}_{3} \mathrm{SiW} / \mathrm{SiO}_{2}$ for five cycles is presented in Fig. 6 (a). As depicted in Fig 6 (a), a significant decrease in catalytic activity was observed after five successive reaction runs, but $43.0 \%$ oleic acid conversion was still achieved. Obviously, it has been found that the Keggin structure of $\mathrm{H}_{4} \mathrm{SiW}$ throughout the reaction was destroyed and also it is clearly evidenced from FT-IR spectral characterization of the catalyst (shown in Fig. 6 (b)). Meanwhile, the decreased activity may be also due to slight loss of the catalyst during separation [28]. According to the obtained results, the $\mathrm{Ni}_{0.5} \mathrm{H}_{3} \mathrm{SiW} / \mathrm{SiO}_{2}$ catalyst possessed a relatively stable.

\subsection{Catalytic activity of $\mathrm{Ni}_{0.5} \mathrm{H}_{3} \mathrm{SiW} / \mathrm{SiO}_{2}$ for other esterification reactions}

More importantly, various FFAs with methanol in esterification were also studied over $\mathrm{Ni}_{0.5} \mathrm{H}_{3} \mathrm{SiW} / \mathrm{SiO}_{2}$ catalyst and the observed results are shown in Table 1. As listed in Table 1,
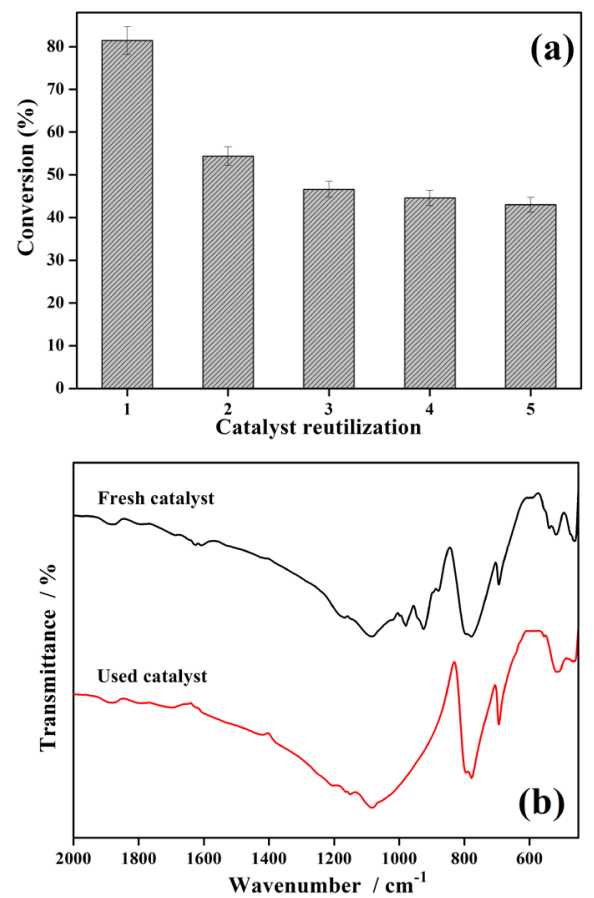

Fig. 6 (a) Recycling experiment of $\mathrm{Ni}_{0.5} \mathrm{H}_{3} \mathrm{SiW} / \mathrm{SiO}_{2}$, and (b) the FT-IR spectra of $\mathrm{Ni}_{0.5} \mathrm{H}_{3} \mathrm{SiW} / \mathrm{SiO}_{2}$ catalysts used and fresh. 
Table 1 Results of other esterifications

\begin{tabular}{lccc}
\hline Entry & Acid & Alcohol & Conversion $/ \%$ \\
\hline 1 & Lauric acid & Methanol & 60.0 \\
2 & Myristic acid & Methanol & 84.3 \\
3 & Palmitic acid & Methanol & 66.7 \\
4 & Stearic acid & Methanol & 60.1 \\
5 & Oleic acid & Methanol & 81.4 \\
\hline
\end{tabular}

it is indicated that the $\mathrm{Ni}_{0.5} \mathrm{H}_{3} \mathrm{SiW} / \mathrm{SiO}_{2}$ catalyst has a good catalytic activity, and holds good potential as solid acid catalyst for the production of biodiesel in industry.

Reaction conditions were $4 \mathrm{~h}$ at $70{ }^{\circ} \mathrm{C}$ with a 1:22 molar ratio FFAs to methanol and 3 wt. $\%$ of $\mathrm{Ni}_{0.5} \mathrm{H}_{3} \mathrm{SiW} / \mathrm{SiO}_{2}$ catalyst.

\section{Conclusion}

In conclusion, the $\mathrm{Ni}$ (II)-exchanged heteropolyacids immobilized on silica $\left(\mathrm{Ni}_{0.5} \mathrm{H}_{3} \mathrm{SiW} / \mathrm{SiO}_{2}\right)$ was successfully prepared as a catalyst for biodiesel production by esterification

\section{References}

[1] Jing, Y. X., Guo, Y., Xia, Q. N., Liu, X. H., Wang, Y. Q. "Catalytic Production of Value-Added Chemicals and Liquid Fuels from Lignocellulosic Biomass", Chem, 5(10), pp. 2520-2546, 2019. https://doi.org/10.1016/j.chempr.2019.05.022

[2] Zhang, Q. Y., Liu, X. F., Yang, T. T., Yue, C. Y., Pu Q. L., Zhang, Y. T. "Facile Synthesis of Polyoxometalates Tethered to Post Fe-BTC Frameworks for Esterification of Free Fatty Acids to Biodiesel", RSC Advances, 9(14), pp. 8113-8120, 2019.

https://doi.org/10.1039/C8RA10574J

[3] Handayani, P. A., Abdullah, A., Hadiyanto, H. "Response Surface Optimization of Biodiesel Production from Nyamplung (Calophyllum inophyllum) Oil Enhanced by Microwave and Ionic liquid+NaOH Catalyst", Periodica Polytechnica Chemical Engineering, 63(3), pp. 406-413, 2019.

https://doi.org/10.3311/PPch.12965

[4] Wang, J. Y., Xing, S. Y., Huang, Y. Q., Fan, P., Fu, J. Y., Yang, G. X., Yang, L. M., Lv, P. M. "Highly Stable Gasified Straw Slag as a Novel Solid Base Catalyst for the Effective Synthesis of Biodiesel: Characteristics and Performance", Applied Energy, 190, pp. 703-712, 2017.

https://doi.org/10.1016/j.apenergy.2017.01.004

[5] Wang, Y. T., Fang, Z., Zhang, F. "Esterification of Oleic Acid to Biodiesel Catalyzed by a Highly Acidic Carbonaceous Catalyst", Catalysis Today, 319, pp. 172-181, 2019.

https://doi.org/10.1016/j.cattod.2018.06.041

[6] Zhang, Q. Y., Yue, C. Y., Pu, Q. L., Yang, T. T., Wu, Z. F., Zhang, Y. T. "Facile Synthesis of Ferric-Modified Phosphomolybdic Acid Composite Catalysts for Biodiesel Production with Response Surface Optimization", ACS Omega 4(5), pp. 9041-9048, 2019. https://doi.org/10.1021/acsomega.9b01037 of oleic acid and methanol. The results indicated that the catalyst had shown excellent catalytic performances with the oleic acid conversion of about $81.4 \%$. Catalytic reusability has been studied and from this it was observed that the catalyst was relatively stable for five cycles. From the kinetic study of esterification reaction, the value $E_{a}$ was found to be $19.2 \mathrm{~kJ} / \mathrm{mol}$. Meanwhile, this catalyst also displayed good catalytic activity in other FFAs esterification. All of these above results indicate that the $\mathrm{Ni}_{0.5} \mathrm{H}_{3} \mathrm{SiW} / \mathrm{SiO}_{2}$ has a great potential for further applications as environmental-benign and sustainable catalysts for biodiesel production.

\section{Acknowledgement}

This work was financially supported by the Technical Talent Support Program of Guizhou Education Department (KY [2018]069), the Key Support Discipline in Agricultural Resources and Environment of Anshun University ([2017]15), and the Creative Research Groups Support Program of Guizhou Education Department (KY [2017]049).

[7] Zhang, H. L., Gao, J. R., Zhao, Z. D., Chen, G. Z., Wu, T., He, F. "Esterification of Fatty Acids from Waste Cooking Oil to Bodiesel over a Sulfonated Resin/PVA Composite", Catalysis Science \& Technology, 6(14), pp. 5590-5598, 2016. https://doi.org/10.1039/C5CY02133B

[8] Cardoso Manique, M., Venturini Lacerda, L., Kopp Alves, A., Pérez Bergmann, C. "Biodiesel Production Using Coal Fly Ash-derived Sodalite as a Heterogeneous Catalyst", Fuel, 190, pp. 268-273, 2017. https://doi.org/10.1016/j.fuel.2016.11.016

[9] Khabinder, P. K., Heer, S., Chabukswar, D. D., Gaikar, V. G. "Intrinsic Kinetics of Esterification of Fatty Acids Catalyzed by Supported Ionic Liquid Catalysts", Chemical Engineering \& Technology, 38(8), pp. 1416-1424, 2015. https://doi.org/10.1002/ceat.201400698

[10] Zhang, Q. Y., Li, H., Yang, S. "Facile and Low-cost Synthesis of Mesoporous Ti-Mo Bi-metal Oxide Catalysts for Biodiesel Production from Esterification of Free Fatty Acids in Jatropha curcas Crude Oil", Journal of Oleo Science, 67(5), pp. 579-588, 2018. https://doi.org/10.5650/jos.ess17231

[11] Zhou, Y., Niu, S. L., Li, J. "Activity of the Carbon-based Heterogeneous Acid Catalyst derived from Bamboo in Esterification of Oleic Acid with Ethanol", Energy Conversion and Management, 114, pp. 188-196, 2016.

https://doi.org/10.1016/j.enconman.2016.02.027

[12] Sharma, Y. C., Singh, B., Korstad, J. "Advancements in Solid Acid Catalysts for Ecofriendly and Economically Viable Synthesis of Biodiesel", Biofuels Bioproducts and Biorefining, 5(1), pp. 69-92, 2011. https://doi.org/10.1002/bbb.253 
[13] Zhang, Q. Y., Yang, T. T., Liu, X. F., Yue, C. Y., Ao, L. F., Deng, T. L., Zhang, Y. T. "Heteropoly acid-encapsulated Metal-Organic Framework as a Stable and Highly Efficient Nanocatalyst for Esterification Reaction", RSC Advances, 9(29), pp. 16357-16365, 2019. https://doi.org/10.1039/C9RA03209F

[14] Lan, J. H., Lin, J. C., Chen, Z. Q., Yin, G. C. "Transformation of 5-Hydroxymethylfurfural (HMF) to Maleic Anhydride by Aerobic Oxidation with Heteropolyacid Catalysis", ACS Catalysis, 5(4), pp. 2035-2041, 2015. https://doi.org/10.1021/cs501776n

[15] Mulik, N. L., Niphadkar, P. S., Pandhare, K. V., Bokade, V. V. " $\mathrm{H}_{\mathrm{x}} \mathrm{Zr}_{3-\mathrm{x}} \mathrm{PW}_{12} \mathrm{O}_{40}$ as an Insoluble and Reusable Heteropolyacid for Highly Selective Dehydration of Fructose to 5-Hydroxymethyl Fufural in DMSO System", Chemistry Select, 3(2), pp. 832-836, 2018. https://doi.org/10.1002/slct.201702669

[16] Kurhade, A., Zhu, J. F., Hu, Y. F., Dalai, A. K. "Surface Investigation of Tungstophosphoric Acid Supported on Ordered Mesoporous Aluminosilicates for Biodiesel Synthesis", ACS Omega, 3(10), pp. 14064-14075, 2018.

https://oi.org/10.1021/acsomega.8b01931

[17] Wang, Y. Q., Zhao, D., Wang, L. L., Wang, X. Q., Li, L. J., Xing, Z. P., Ji, N., Liu, S. J., Ding, H. "Immobilized Phosphotungstic Acid based Ionic Liquid: Application for Heterogeneous Esterification of Palmitic Acid", Fuel, 216, pp. 364-370, 2018. https://doi.org/10.1016/j.fuel.2017.11.153

[18] Ekinci, E. K., Oktar, N. "Production of Value-added Chemicals from Esterification of Waste Glycerol over MCM-41 supported Catalysts", Green Processing and Synthesis, 8(1), pp. 128-134, 2019. https://doi.org/10.1515/gps-2018-0034

[19] Han, X. X., Chen, K. K., Yan, W., Hung, C. T., Liu, L. L., Wu, P. H., Lin, K. C., Liu, S. B. "Amino Acid-functionalized Heteropolyacids as Efficient and Recyclable Catalysts for Esterification of Palmitic Acid to Biodiesel", Fuel, 165, pp. 115-122, 2016. https://doi.org/10.1016/j.fuel.2015.10.027

[20] International Organization for Standardization "ISO 660-2009 Animal and vegetable fats and oils-Determination of acid value and acidity", ISO, Geneva, Switzerland, 2009. [online] Available at: https://www.iso.org/standard/44879.html [Accessed: 19 October 2019]
[21] Parida, K. M., Mallick, S. "Silicotungstic Acid supported Zirconia: An Effective Catalyst for Esterification Reaction", Journal of Molecular Catalysis A: Chemical, 275(1-2), pp. 77-83, 2007. https://doi.org/10.1016/j.molcata.2007.05.022

[22] Liu, Y., Zhang, P. B., Fan, M. M., Jiang, P. P. "Biodiesel Production from Soybean Oil Catalyzed by Magnetic Nanoparticle $\mathrm{MgFe}_{2} \mathrm{O}_{4} @$ CaO", Fuel, 164, pp. 314-321, 2016.

https://doi.org/10.1016/j.fuel.2015.10.008

[23] Wang, L. T., Dong, X. Q., Jiang, H. X., Li, G. M., Zhang, M. H. "Ordered Mesoporous Carbon supported Ferric Sulfate: A Novel Catalyst for the Esterification of Free Fatty Acids in Waste Cooking Oil", Fuel Processing Technology, 128, pp. 10-16, 2014. https://doi.org/10.1016/j.fuproc.2014.06.023

[24] Brahmkhatri, V., Patel, A. "Esterification of Lauric Acid with Butanol-1 over $\mathrm{H}_{3} \mathrm{PW}_{12} \mathrm{O}_{40}$ Supported on MCM-41", Fuel, 102, pp. 72-77, 2012. https://doi.org/10.1016/j.fuel.2012.05.053

[25] Fadhil, A. B., Aziz, A. M., Al-Tamer, M. H. "Biodiesel Production from Silybum marianum L. seed oil with High FFA Content Using Sulfonated Carbon Catalyst for Esterification and Base Catalyst for Transesterification", Energy Conversion and Management, 108, pp. 255-265, 2016 https://doi.org/10.1016/j.enconman.2015.11.013

[26] Bedard, J., Chiang, H., Bhan, A. "Kinetics and Mechanism of Acetic Acid Esterification with Ethanol on Zeolites", Journal of Catalysis, 290, pp. 210-219, 2012. https://doi.org/10.1016/j.jcat.2012.03.020

[27] Patel, A., Brahmkhatri, V. "Kinetic Study of Oleic Acid Esterification over 12-tungstophosphoric Acid Catalyst Anchored to Different Mesoporous Silica Supports", Fuel Processing Technology, 113, pp. 141-149, 2013. https://doi.org/10.1016/j.fuproc.2013.03.022

[28] Vahid, B. R., Haghighi, M., Toghiani, J., Alaei, S. "HybridCoprecipitation vs. Combustion Synthesis of Mg-Al Spinel Based Nanocatalyst for Efficient Biodiesel Production", Energy Conversion and Management, 160, pp. 220-229, 2018. https://doi.org/10.1016/j.enconman.2018.01.030 